Session 2561

\title{
Bachelor of Arts in Engineering Program at the University of Arizona
}

\author{
Jeff Goldberg \\ Director, Bachelor of Arts in Engineering Program \\ College of Engineering and Mines \\ University of Arizona
}

\begin{abstract}
In this paper, we report the progress of the Bachelor of Arts in Engineering (BAE) Program (formerly named the ELITE program - Engineering with LIberal and Technical Education). The program is novel in that it leads to a BA in Engineering degree at the University of Arizona, a large land-grant institution. We have 25 students and we are becoming more established on campus with each additional semester. We have had 24 graduates with placement in both industry and graduate school. Each year approximately 60 students hear our informational presentations and seek information about the program.

The program allows students exceptional flexibility in designing a degree program to meet their needs. Requirements ensure that the students cover areas within engineering and outside of engineering and we focus on the application of technology. Our requirements are designed to be agile in that students can quickly piece together degree programs in "hot" areas.

We have formulated research questions based on the needs of our key stakeholders. In this report, we present initial findings on three of the questions. Our results suggest that we are achieving our mission of keeping high quality students in engineering related fields and we have succeeded at developing and operating a program that allows students an opportunity to tailor an educational experience to their direct needs. We also have areas where we could improve, and suggestions and strategies are included.
\end{abstract}

\section{Introduction}

Innovative applications of engineering methodology have opened new avenues in several nontraditional areas. For example, the term financial engineering has been coined to describe activities related to the design of new financial instruments. Similarly, the latest entertainment spectacle at Disneyland (the Indiana Jones Adventure) is credited to an activity that the Walt Disney Company refers to as imagineering. This term refers to an entire spectrum of activities ranging from master-planning and creative development to video production, audio/lighting design, and on-board vehicle performance. In addition, traditional engineering analyses such as those exploring the impact of layout on customer flow through the attraction were of critical 
importance in the design of the facility. Given the diversity of activities involved in this particular venture, it is not surprising that the head of the imagineering project has a degree in Industrial and Systems Engineering, the engineering discipline which typically affords the greatest degree of breadth and diversity.

Current engineering curricula at most major US universities are not designed to provide the kind of breadth that is necessary to apply engineering concepts of design and analysis in non-traditional settings such as those suggested above. Borrowing from the 1997 Professional Activities Conference of the IEEE [1]

"Society looks upon engineers with a great deal of ambivalence. Our preparation for the engineering profession in the United States, does not match the rigor of European universities. It does not meet the rigor of the medical or legal professions in the United States. We have no apprenticeship program as do medicine and law. Also, our education is generally devoid of the humanities. Our education is not only essentially technical but, in recent years, has suffered from lack of breadth. It has become specialized and tends toward the high-level trade school approach."

The problem of narrowness has been similarly discussed in Australia as shown by the following statements from The University of Western Australia [2]:

"The insularity of engineering students and the prejudices that go with that are detrimental to the aim of producing Engineering graduates who can recognize the validity of others' points of view and are able to make responsible judgments in areas outside the technical aspects of Engineering. Allowing Engineering students to participate in other disciplines would not only give them the opportunity to follow their interests and learn different skills, but would also expose them to alternative views of the world. It would also help them to see Engineering in the context of other important, valid disciplines."

"The perceptions and prejudices that students and staff outside Engineering form about engineering students have a detrimental effect on the perceptions of society about engineers. When they graduate, engineering students will work with other professionals in a wide range of disciplines. Doctors, scientists, architects, lawyers, urban planners, designers and other professionals of the future are being trained alongside engineering students at this university. Their perceptions of engineers are being formulated now, by what they see. Unless they work alongside Engineering students in combined courses, what they tend to see is the dominant culture."

Breadth is often attained through extensive on-the-job training (or even retraining), or through the completion of multiple degree programs in diverse areas such as engineering, business, medicine, law, etc. There have been some attempts to broaden engineering education. For example, the Succeed Coalition Early Design Megaproject [3] has the goal to:

"prepare students for the 21 st century workplace by exposing them to the 
dynamics of small, entrepreneurial companies, which are expected to generate most new jobs in the foreseeable future. Engineering graduates are traditionally illprepared to function well in small, entrepreneurial companies where a breadth of knowledge and skills is more valuable than depth. Yet, job market growth in recent years has nearly all come from small companies, and most economists predict this trend to continue into the 21 st century."

The large majority of current curricula, however, do not provide the benefits of an engineering perspective to those who do not anticipate a traditional career in engineering. There are however programs similar to ours including:

- University of Rochester Bachelor Of Arts In Engineering Science - intended for students who, while not necessarily planning careers in the practice of engineering, may benefit from an enhanced technical content in their education. The B.A. in engineering science emphasizes breadth across engineering disciplines. http://www.rochester.edu/Bulletin/Engineering/baengsci.html

- Dartmouth College - Bachelor of Arts - The undergraduate engineering degree at Dartmouth is the Bachelor of Arts (A.B.) with a major in engineering sciences.

The program tries to integrate engineering students into all aspects of a liberal arts college and emphasizes the basic scientific principles found in all fields of engineering. Students specialize through electives as their interests become more defined. http://engineering.dartmouth.edu/thayer/academicsadmissions/undergrad-ba.html

- Lafayette College - Bachelor Of Arts Degree With A Major In Engineering - This program is not intended for students who wish to practice as engineers. Rather, these students move to careers in management, law, architecture, public policy, medicine and other fields in which their technical background is a recognized asset. The program not ABET accredited as an engineering degree however, it has breadth where the Bachelor of Science program has depth. http://ww2.lafayette.edu/ rosenbau/eng html/ab.htm

- Tufts University - Combined Degree Programs Combined Five-Year Liberal ArtsEngineering Program. For some students picking between liberal arts and engineering is difficult. For them, both the professional flavor and occupational orientation of the engineering programs on the one hand, and the variety of course selection in the liberal arts curriculum on the other, have strong appeal. This program is designed for civil and environmental engineering students to secure the advantages of both under the combined five-year program. http://ase.tufts.edu/cee/undergraduate/combined.asp

- Rice University - Bachelor of Arts in Electrical. The Bachelor of Arts degree provides a basic foundation in electrical and computer engineering and a large number of free electives so that students can easily participate in another major to create an interdisciplinary program. This may be particularly appropriate for students planning further study in law, business, or medicine. Combining the B.A. degree with humanities creates a broad, liberal education program with an engineering focus. http://www.ece.rice.edu/ece/undergrad-info/program.html

Note that the above programs tend to be a small private schools. We believe that our program is unique in that we operate a large state land-grant university. The BAE Degree Program at the 
University of Arizona has been in operation since it was funded by NSF in 1996. The program is designed to provide the capable and motivated student with an excellent grounding in the liberal arts that is thoroughly integrated with mastery of the skills and concepts that are fundamental to modern engineering thought. The program is designed to enable students to choose their professional or career directions from a much wider range of options than are typically available via traditional engineering curricula. The Program has the following mission statement:

The BAE program provides a vehicle by which students can plan a course of study that reflects their interests in the arts, humanities, business and social sciences, and applications of engineering methods to these disciplines. By providing a well-rounded education, the BAE program will prepare graduates who have the breadth of vision to lead this nation into the 21st century. Graduates of this program are expected to be involved in the engineering services, with applications in banking, entertainment, finance, healthcare, public policy and many others.

The remainder of the paper is organized as follows. In section 2, we will give a brief overview of design of the program. In section 3 we give the objectives and outcomes of the program as well as the current status. Section 4 includes some of our program evaluation covering both graduates as well as current students. We conclude in section 5 with observations of what we might have done better during the past 7 years.

\section{Program Design}

The design of the BAE program has been greatly influenced by the national debate over the need for well-rounded education for engineers and the lack of programs that provide such an education. Here are typical quotes from a variety of individuals and organizations:

- A. Blanton Godfrey [4] - "Many organizations find it easier to create the title chief quality officer than to find someone who can actually do the job." "It is common now to see new vice presidents of quality with strong business skills or human resource skills put in over the traditional quality director with strong technical skills."

- Norman Augustine - CEO Lockheed Martin [5] - "Generally speaking they're (engineering students) very well prepared in their own discipline. And also in the fundamentals, math or literature. If I broaden from the students I'm teaching, just to the general group of graduates in college today, I would say the principal shortcoming of the engineering students is a lack of breadth in terms of their ability to communicate in writing, verbally, [and] their lack of background in public policy issues, political science issues, those things that affect engineering. Just as the laws of physics affect engineering, so, too, do the laws of the land. And engineers and scientists. . have generally been relatively inept at dealing with those things. "

- Ralph Castain, Manager of Strategic Forecasting at Eaton Corporation [6]. "Probably the most useful part of my education has been its broad nature, and that's where Harvey Mudd College has contributed the most. I have to pull in a wide variety of areas, and am continually surprised at the lack of breadth I find in those educated at the larger state universities." 
- Sharon Bender, university professor [7] - "If engineers are to be more than technical functionaries in the next millenium there is a need to provide young engineers with an understanding of the social context within which they will work, together with skills in critical analysis and ethical judgement, and an ability to assess the long term consequences of their work. Engineering in the modern world also involves many social skills. These include the ability to understand and realise community goals, to persuade relevant authorities of the benefits of investing money in engineering projects, to mobilise, organise and coordinate human, financial and physical resources, to communicate and motivate, and to advise on many social, environmental and safety aspects of their work

- US Board on Engineering Education [8] - "There is a widening recognition of the responsibility of engineers to consider the social and environmental impact of their work. In sharp contrast to the attitudes and practices that prevailed at mid-century and before, engineers today are required to design sustainable systems that consider as crucial inputs the environmental impact of their manufacture and use, their accessibility to people of diverse ethnicity and physical abilities, their safety, and their recyclability."

- Institution of Engineers, Canberra Australia, Review of Engineering Education [9] - "In the business world, engineers are often seen as being preoccupied with technical issues to the exclusion of all else, unwilling or unable to appreciate contextual imperatives or to contribute effectively to business and political decisions. This has probably been the main factor leading to the 'de-engineering' of the public sector, and to the view of engineering as a commodity to be purchased when needed and not a critical strategic capability requiring long-term investment and development, or an integral part of decision-making. (Review of Engineering Education

The above opinions called for "the creation of a new cadre of students and faculty characterized by (1) interest in, and knowledge of, real problems and their societal, economic and political context; (2) an ability to function effectively as members of a team creating new products, processes and systems; (3) an ability to operate effectively beyond the confines of a single discipline; and (4) the integration of a deep understanding of science and technology with practical knowledge, a hands-on orientation, and experimental skills and insight. In order to meet these goals, some educators are calling for five year engineering programs, whereas, others suggest that some technical material may have to be eliminated.

The BAE program is designed to lead to a BA in Engineering after completing 120 credit hours. These credit hours include the UA general education requirements, as well as the freshmanengineering core required by the College of Engineering and Mines (CoEM). In addition, all students must complete a common set of courses designed to promote basic engineering skills, a series of seminar courses, and a senior project. Beyond these requirements, the students are free to define a technical focus area and a complementary area that is non-technical. The focus area must be comprised of a cohesive set of courses that relate to a common technological theme. We expect a majority of these courses to be drawn from CoEM course offerings. A complementary area may be drawn from virtually any of the university's vast course offerings, although the student must demonstrate a common theme that complements the focus area. Note that neither the focus nor complementary areas need be defined in terms of established UA departments or programs. A student may opt to define them in such a manner as to explore a theme from a 
variety of perspectives.

The BAE program at Arizona has the following specific components (all credits are semester credits):

- General Education - The University requires 4 tier-I level courses in the topics of individuals and society and traditions and culture and 3 tier-II level courses in arts, humanities, and individuals and society. This totals 21 credits, however 3 of these can be used to satisfy other requirements in a student's program

- Foreign Language - 4 semesters of foreign language. Students already have 2 semesters from high school as a University entrance requirement so this totals 8 credits.

- Math - 3 calculus courses totaling 10 credits

- Math/Communication Elective - an additional 3-credit math or communications course. The selection depends on the remainder of the student's program as some engineering classes require differential equations while some computer classes require discrete mathematics.

- Science - 3 lab (12 credits) science courses. Students working in electrical areas generally take 2 physics courses and 1 chemistry course. Students working in environmental/chemical areas take 2 chemistry courses and 1 biology course. Other students take some mix of chemistry, biology, and physics.

- Writing - 2 freshman writing courses and a junior course in technical writing. This totals 9 credits.

- Basic Engineering - Students must take 3 credits in freshman engineering, 3 credits in computer programming, and 6 credits in sophomore engineering courses. These final 6 units are electives that are chosen from the traditional engineering science courses as well engineering probability and statistics.

- Focus Area - Students take 24 credits in engineering courses in an area of interest. The courses are not constrained by traditional department boundaries; however they must be related thematically. These are chosen by the student with the help of an advisor

- Complementary Area - Students take 12 credits in courses in an area that is outside of engineering. The area is chosen as a complement to the focus area and generally is an area where the focus area technology can be applied. These courses are tied thematically and have been in areas such as media arts, music, theater, art, anthropology, public policy, finance, general business, political science, and education

- Senior Design - Each student must complete a 3-credit senior design project that includes a project proposal, a final report, and a final presentation. Some students work with the traditional department senior design project classes while others develop projects on their own. The large majority of projects are team based and BAE program students team with students from engineering as well as other programs.

- Seminar - Students must complete 9 units of material that clearly integrates engineering/technology with other areas. These can include university courses (the BAE program has supported the development and offering of 12 such courses), independent study projects with a non-engineering faculty member, and summer job/co-op experience where the student submits a proposal and a final report and makes a presentation about the experience. 
The total number of units in the program is 123 credits, however since 3 can be double counted, students graduate with 120 credits. All other programs in the College require 128 units. All BA programs in the University have 120 credits and the leadership team decided that this was better for student recruiting and differentiation from the BS programs in the College. Note that by Arizona Board of Regents policy University of Arizona programs with more than 128 credits cannot be advertised as a 4-year program. There are no programs other than the architecture professional program that has more than 128 credits.

The program is not ABET accredited and this was a critical design decision (that is reviewed regularly!). The main difficulty is in ABET Criteria 4 which requires 30 credits of math and science and 45 units of engineering science and design. The program has only 25 math and science credits and 39 engineering credits. This assumes that the seminar courses as well as all of the complementary area materials do not count towards any ABET engineering or math requirements. We could attempt to make the argument to count some credits in these courses, however some complementary areas as well as seminar courses have little to no engineering and math content and hence eliminating these options would prove restrictive to some students (and difficult to enforce uniformly). Increasing the requirements to 128 credits would not be sufficient to meet ABET Criteria 4 requirements. Other similar programs are not accredited (Dartmouth and Lafayette for example) and this does not seem to be detrimental. At Arizona, Engineering Math and Engineering Physics do not have ABET accreditation and these programs have been successful. It is not clear that this has been an issue for our students. We have had students sit for the FE exam and we have had students placed in graduate schools and industry. We do outcome based evaluation and this is the major feature of EC 2000. We may choose to make the argument and ask for a variance to Criteria 4 , but that is a future issue.

\section{BAE Program Objectives and Outcomes}

The BAE program has no faculty assigned and offers no classes (we have supported course development, but funding issues severely limit this option. All students take regular university classes and are advised and mentored by faculty in other programs. Each student has a different program. Hence it is difficult to design an evaluation system based on a standard set of specific courses.

Based on the mission of giving students opportunities they would not have in more traditional engineering programs, we have arrived at the following program objectives, outcomes, and metrics (standard for each metric is listed in parentheses after the description): 
BAE Program Objective 1 - To educate and graduate high quality students that are desired by both industry and graduate schools and become lifelong learners.

Outcome 1.1 - Students should be placed in jobs that make use of their broad skills Metrics:

- $\%$ of students placed in permanent jobs within 3 months after graduation $(>75 \%)$

- $\%$ of students that have had a focus/complementary area related co-op/internship position during their undergraduate career $(>50 \%)$

Outcome 1.2 - Students should be placed in high quality graduate school programs and continue to be life long learners

\section{Metrics:}

- $\%$ of students that go directly to graduate school upon graduation to a program that is a University of Arizona engineering peer or a Research I University $(>15 \%)$

- $\%$ of students that earn an advanced degree or a degree in a different field within 7 years of graduation $(>50 \%)$

Outcome 1.3 - Students should be of high academic quality and should be successful in engineering and non-engineering classes in their programs

Metrics:

- $\%$ of students that graduate with a 3.5 GPA or better $(>30 \%)$

- $\%$ of students that graduate with a 3.25 GPA or better in focus area courses $(>50 \%)$

- $\%$ of students that graduate with a 3.25 GPA or better in complementary area courses $(>50 \%)$

- $\%$ of students that graduate with a $3.25 \mathrm{GPA}$ or better in math/science courses $(>50 \%)$

- $\%$ of students making the Dean's List each semester $(>25 \%)$

- $\%$ of seniors in each year that are nominated for "outstanding senior" awards ( $>1$ per year)

- $\%$ of students that have a cumulative GPA for all semesters in the program that is 0.5 points higher than their entering GPA, given that they had below a 2.75 GPA when entering the program $(>33 \%)$

BAE Program Objective 2 - To provide an enriching experience for each student so that they can study in diverse areas of interest.

Outcome 2.1 - Students should have opportunities in fine arts, humanities, social science, and business.

Metrics:

- $\%$ of students doing a complementary area in fine arts $(>20 \%)$

- $\%$ of students doing a complementary area in humanities $(>10 \%)$

- $\%$ of students doing a complementary area in social science $(>10 \%)$

- $\%$ of students doing a complementary area in business (>20\%) 
Outcome 2.2 - Students should have opportunities to work in non-traditional technical focus areas.

Metrics:

- $\%$ of students whose focus area spans classes taught in 2 or more traditional engineering departments $(>50 \%)$

Outcome 2.3 - Students should have opportunities for independent study and to work on research projects.

Metrics:

- $\%$ of students that participate in independent study and/research projects as part of the 9 unit BAE course requirements $(>75 \%)$

- $\%$ of students that participate in a research project with a faculty member $(>50 \%)$

Outcome 2.4 - Students should enjoy their experiences in the program and feel that they made a good decision in selecting the program

\section{Metrics:}

- $\%$ of graduates that self-rate scores of excellent or very good for the alumni survey question "How well do you feel that the BAE program prepared you for employment/graduate school?" (> 80\%)

- $\%$ of graduates that self-rate scores of excellent or very good for the alumni survey question " How well were you satisfied with your overall experience in the BAE program at Arizona?" (> 80\%)

BAE Program Objective 3 - Students should be effective team members and act in a professional manner. This includes teamwork skills as well as communication skills.

Outcome 3.1 - The students should understand roles, advantages, disadvantages and dynamics of teams and have successful experience on team projects.

\section{Metrics:}

- Senior design project log and team assessment. (all students complete this)

Outcome 3.2 - Students should be able to communicate effectively with team members and clients through both oral and written means.

\section{Metrics:}

- Grade in ENG 307 or ENG 308 (> 80\% get A or B)

- Instructor analysis of oral presentations in senior design final presentation, $\%$ of students that score in the top two categories (very good or excellent) $(>80 \%)$

- $\%$ of students that score in the top two categories (very good or excellent) on the entrance paragraph requirement. $(>80 \%)$

Outcome 3.3 - The students should be able to deal with clients (including instructors) in a professional manner covering demeanor, presentation style, and work ethic.

\section{Metrics:}

- Client evaluation reports for senior projects - \% of students that score in the top two categories (very good or excellent) $(>80 \%)$ 
- Supervisor evaluation reports for Co-op projects - \% of students that score in the top two categories (very good or excellent) $(>80 \%)$

Outcome 3.4 - The students should be able to differentiate between ethical and unethical behavior.

\section{Metrics:}

- Score on an ethics exam developed from mini-case situations from Lockheed Martin $(90 \%$ of students should score $>75 \%)$

BAE Program Objective 4 - The BAE program should serve a diverse student population in terms of interests, backgrounds, and abilities.

Outcome 4.1 - The student recruiting processes of the program should have multiple sources and reach a diverse population

\section{Metrics:}

- Number of students that make office visits or attend BAE information seminars $(>75$ per year)

- Fraction of attendees/visitors that are women (>30\%)

- Fraction of attendees/visitors that are from other underrepresented groups $(>20 \%)$

Outcome 4.2 - Graduates of the program should be from a diverse population of people and engineering interests

\section{Metrics:}

- Percentage of program graduates that are from underrepresented groups $(>50 \%)$

- $\%$ of graduates that have the same focus area $(<25 \%)$

Outcome 4.3 - Students should have opportunities in fine arts, humanities, social science, and business (same as outcome 2.1).

\section{Metrics:}

- $\%$ of students doing a complementary area in fine arts $(>20 \%)$

- $\%$ of students doing a complementary area in humanities $(>10 \%)$

- $\%$ of students doing a complementary area in social science $(>10 \%)$

- $\%$ of students doing a complementary area in business $(>20 \%)$

The metrics represent a collection of exam scores, course grades (or grade averages), and opportunities for experience. We collect most of this data on a semester by semester basis and review progress with individual students each semester.

\section{Program Status and Evaluation}

In the initial stages of the program, many research questions were formulated and we report on three at this point:

1. Does BAE help produce high quality graduates?

2. What types of students enter the BAE program? 
3. Why do students choose to enter BAE and what types of programs are they interested in?

Much of our initial evaluation has been geared towards developing insight on these questions.

4.1 High Quality Graduates - The measures of high quality are the metrics associated with Outcomes 1.1, 1.2, and 1.3. To date, we have had 24 graduates and their placements are listed in Table 1 .

Table 1 - Graduates of the Program

\begin{tabular}{|c|c|c|c|c|}
\hline$\#$ & Focus/Complemenary Areas & $\begin{array}{l}\text { Grad } \\
\text { Date }\end{array}$ & $\begin{array}{c}\text { Current Company Name or } \\
\text { Graduate School }\end{array}$ & $\begin{array}{l}\text { Eth. } \\
\text { Sex }\end{array}$ \\
\hline 1 & Material Science / Anthropology & F 98 & UCAN/Privacy Rights Clearinghouse CA & W F \\
\hline 2 & GIS / General Business & S 99 & Intuit / Univ. of Arizona Nursing - AZ & W F \\
\hline 3 & Computer Science / Finance & S 00 & InvestElite - NY & W M \\
\hline 4 & Operations Research / Org. Behav. & S 00 & Univ. of Arizona - Systems Engr. - AZ & $\mathrm{OF}$ \\
\hline 5 & Operations Research / Finance & S 00 & Motorola - AZ & $\mathrm{OF}$ \\
\hline 6 & Aerospace Engr / Astronomy & S 00 & SpectrumAstro - AZ & $\mathrm{OM}$ \\
\hline 7 & Digital Sys.- Hum. Factors / Music & S 01 & No data & W M \\
\hline 8 & Environ. Engr. / Public Policy & S 01 & Environmental Group - Portland, OR & W F \\
\hline 9 & Aerospace Engr. / Economics & S 01 & Lockheed Martin - FL & $\mathrm{BM}$ \\
\hline 10 & Biosystems Engr. / Public Policy & S 01 & Stanford University - EES/OR - CA & W F \\
\hline 11 & Operations Research / Finance & S 01 & Comair Airlines, Inc. - Cincinnati OH & W M \\
\hline 12 & Computer Engineering / Music & F 01 & IBM - Tucs on AZ & W M \\
\hline 13 & ChEE / Japanese Culture & S 02 & UMC/Arthritis Center - Tucson AZ & W M \\
\hline 14 & Systems / Business & S 02 & No data & W M \\
\hline 15 & Civil Engineering / Arch history & S 02 & Rick Engineering - Tucson AZ & $\mathrm{HF}$ \\
\hline 16 & SIE / Fashion Design & S 02 & IMG Talent Agency - CA & W F \\
\hline 17 & Industrial Engr. / Entertainment & S 02 & Premiere Radio Networks - CA & W F \\
\hline 18 & Chemical Engineering / Finance & S 02 & No data & $\mathrm{W} \mathrm{M}$ \\
\hline 19 & Industrial Engineering / Finance & S 02 & Raytheon - Tucs on AZ & W F \\
\hline 20 & Quality Control / Business & $\mathrm{Su} 02$ & Walgreens/Distribution - Flagstaff AZ & $\mathrm{NM}$ \\
\hline 21 & Computer Engr. / Media Arts & Su 02 & Consultant - NYC & W M \\
\hline 22 & Software Engr. / Multi-Media & F 02 & Raytheon - Tucs on AZ & HM \\
\hline 23 & Industrial Engr. / Business Admin & F 02 & Raytheon - Tucson AZ & $\mathrm{HM}$ \\
\hline 24 & Elec. \& Comp. Engr/ Politcal Sci & F 02 & Owns own web business - Tucson, AZ & W M \\
\hline
\end{tabular}

$\mathrm{W}=$ White $\quad \mathrm{O}=$ Oriental $\quad \begin{gathered}\mathrm{B}=\text { Black } \\ \mathrm{M}=\text { Male }\end{gathered} \quad \begin{gathered}\mathrm{H}=\text { Hispanic } \\ \mathrm{F}=\text { Female }\end{gathered} \quad \mathrm{N}=$ Native American

Currently, we have three students that are as yet unplaced or we do not have any reported data (student 7 and student 18). Outcome 1.1 seems to be met. The types of jobs that the students take range from traditional engineering jobs (students 9 and 6 for example) to areas where engineering students are rarely placed (students 16, 17, 3). Some students have been placed in positions that require the specific skills developed in the BAE program (students 12 and 19).

Overall, we have been happy with placement, especially considering that we are in a down market 
for engineering graduates (spring 2002 had a 50\% drop in new engineering jobs in manufacturing).

Presently, three of the graduates have returned to graduate school or professional school. Two others are considering law school and an advanced degree in education. Given the young age of the program, we feel that this result is in line with outcome 1.2. Table 2 lists various grade point averages of the graduates.

Table 2. - GPA Metrics for Graduates

\begin{tabular}{|c|c|c|c|c|}
\hline$\#$ & Overall GPA & Focus Area GPA & $\begin{array}{c}\text { Complementary } \\
\text { Area GPA }\end{array}$ & $\begin{array}{c}\text { Math/Sci/Basic } \\
\text { Engineering } \\
\text { GPA }\end{array}$ \\
\hline 1 & & & 3.750 & 3.261 \\
2 & 3.325 & 3.000 & $\mathbf{4 . 0 0 0}$ & $\mathbf{4 . 0 0 0}$ \\
3 & $\mathbf{3 . 9 0 2}$ & $\mathbf{4 . 0 0 0}$ & 3.000 & 2.704 \\
4 & 3.032 & 2.600 & $\mathbf{4 . 0 0 0}$ & $\mathbf{4 . 0 0 0}$ \\
5 & $\mathbf{3 . 8 9 6}$ & $\mathbf{3 . 8 7 5}$ & $\mathbf{4 . 0 0 0}$ & $\mathbf{4 . 0 0 0}$ \\
\hline 6 & $\mathbf{4 . 8 8 0}$ & $\mathbf{3 . 5 0 0}$ & $\mathbf{3 . 2 5 0}$ & $\mathbf{4 . 0 0 0}$ \\
7 & $\mathbf{3 . 7 3 3}$ & 2.917 & 3.250 & 2.440 \\
8 & 2.943 & 2.550 & 3.000 & 2.769 \\
9 & 3.016 & 1.875 & 2.500 & 2.333 \\
10 & 2.285 & $\mathbf{3 . 8 5 7}$ & $\mathbf{4 . 0 0 0}$ & $\mathbf{3 . 6 3 6}$ \\
\hline 11 & $\mathbf{3 . 7 6 9}$ & 2.125 & $\mathbf{3 . 2 5 0}$ & $\mathbf{3 . 2 5 0}$ \\
12 & 3.432 & 2.500 & $\mathbf{4 . 0 0 0}$ & 2.760 \\
13 & 2.752 & $\mathbf{3 . 8 8 0}$ & $\mathbf{3 . 5 0 0}$ & $\mathbf{3 . 6 1 9}$ \\
14 & 2.351 & 2.750 & $\mathbf{3 . 5 0 0}$ & $\mathbf{3 . 2 8 6}$ \\
15 & $\mathbf{3 . 5 8 1}$ & $\mathbf{3 . 5 5 0}$ & $\mathbf{3 . 3 3 3}$ & 3.458 \\
\hline 16 & 3.134 & $\mathbf{4 . 0 0 0}$ & $\mathbf{4 . 0 0 0}$ & $\mathbf{3 . 3 6 0}$ \\
17 & $\mathbf{3 . 5 8 2}$ & 1.875 & 3.000 & $\mathbf{3 . 8 5 7}$ \\
18 & $\mathbf{3 . 9 3 7}$ & $\mathbf{4 . 0 0 0}$ & $\mathbf{3 . 5 0 0}$ & 2.680 \\
19 & 2.130 & 3.160 & $\mathbf{3 . 2 5 0}$ & $\mathbf{3 . 7 7 8}$ \\
20 & $\mathbf{3 . 8 3 2}$ & 3.038 & $\mathbf{3 . 5 0 0}$ & 2.963 \\
\hline 21 & 3.151 & Not Yet Avail & $\mathbf{4 . 0 0 0}$ & Not Yet Avail \\
22 & 2.843 & 2.958 & 3.000 & Not Yet Avail \\
23 & $\mathbf{3 . 6 3 6}$ & $\mathbf{3 . 7 5 0}$ & $\mathbf{3 . 5 1 9}$ \\
\hline 24 & 2.846 & $\mathbf{3 . 5 0 0}$ & & \\
\hline
\end{tabular}

We can compute the metrics standards for outcome 1.3 (bolded values on Table 2 are students that have met the standards):

- 3.5 for Overall GPA

- 3.25 for Focus Area GPA

- 3.25 for Complementary Area GPA

- 3.25 for Math/Science/Basic Engineering GPA
(10 out of 22)

(10 out of 22)

(16 out of 24)

(12 out of 22) 
It is clear we have some high GPA graduates and that generally students are not using the program as an "easy way to complete" engineering. Graduates typically enjoy the complementary area courses and this translates into higher grades in those classes. Also, the students do well in math, science, and basic engineering. Since these courses are the typical "weed-out" classes, most of our students are entering into the program by preference and not as a last resort.

4.2 Types of Students - Currently, we have 25 students in the program and we seem to be in a steady state fluctuating between 22 and 30 students. Almost all students come to us at the end of some semester and that can be in any of the students' first four semesters at the University.

Every current UA student that sets up a meeting to hear about the program is dissatisfied with their current program and is looking for alternatives. We also get a few high school seniors/community college transfers that visit and enroll in the program, however these are clearly in the minority as this is not our primary recruiting target. The high school seniors that come to us are generally top students and have a fine arts component. This is similar to what the UA Honors College sees in top high school students. We also get students entering the program at the 6 semester mark and these are usually students that are looking for a quick way to graduate.

Our graduation statistics show that ten of our graduates are women and five students are from other traditionally underrepresented ethnic groups (we do not consider "oriental" to be underrepresented). Our recruiting evaluations show that these percentages hold over all students that visit the program for information.

Fifty-eight students that asked for information in AY 2001-2002 and of those, 28 found us from an Engineering Open House/Orientation and 18 first learned about the program from the web site or the UA online catalog. Women made up $45 \%$ of the group and $41 \%$ were from underrepresented ethinic groups. The average SAT score totaled 1158 and this compares quite favorably with the COEM average of around 1100. The students' current GPA's have variation, but in general are lower than average ( 2.56 on a 4.0 scale). This is indicative of students that are dissatisfied with their current majors. Students in their freshman year made up $40 \%$ of the visits and there were only four transfer students from other schools. The students were currently in a variety of majors including all of the traditional engineering majors as well as Journalism, Creative Writing, Architecture, Media Arts, Spanish, Business, and Mathematics. Also, 28\% of the visits were from students that were currently in an "undecided" major. It is clear that the program is gaining broad appeal and a variety of students of all interests and abilities are obtaining information.

4.3 Entrance Reasons and Program Variety - Generally the flexibility of the program is the key benefit from the students' side (especially if they are trying to expedite graduation) and the main drawback is job and placement uncertainty. As we now have a short history of successful placement, we are able to alleviate fears somewhat, but this is a major student issue. We explore entrance reasons by surveying students when the come for a first appointment/presentation.

Program variety is tied to outcomes $4.1,4.2$, and 4.3. From Table 1 , we see that the complementary areas of the graduates cover liberal arts/social sciences ( 5 students), fine arts and 
media arts (6 students), and business/public policy (12 students). Recently, we have had fewer students going into business and this trend will continue as the business school has restricted enrollment from out-of-business-college students and there is a new Engineering Management program in the Engineering College. The focus areas include a variety of engineering disciplines and all are hybrids of the traditional programs. For example, students in computer science typically combine traditional programming courses with courses in artificial intelligence. The most traditional programs are those students that are using industrial and systems engineering as a focus area.

\section{Lessons Learned and Strategies for Success}

We had some difficulties in getting the program started and in keeping our focus. We had a great deal of help and guidance from the NSF visiting committee as they pointed out key issues. We conclude this paper with a few of the critical needs for success:

Program mission and target audience - The key point made by the national visiting committee was that the mission and goals of the program must be better specified. Initially, we keyed the program to "high end" students and less so to the broad range of students. However, from the start, our main goal was to offer students an alternative to the standard engineering programs. Clearly, this should be inclusive of students of all abilities. We are looking for students that are dissatisfied with their current program, but want to remain in the College. We changed the name of the program from ELITE to BAE and we changed our advertising materials to reflect our interest in diversity and focused our recruiting efforts to a broader spectrum of students. Also, by increasing our student interest base, we have the potential for enrollment growth

Initially our primary focus was on the Business College as a primary complementary area (much of our recruiting went down this path). This is really not in line with the breadth idea in the program. Students that want this direction probably should be in an engineering management program or industrial engineering type programs. Finally this faculty group does not seem to be interested (no faculty seminars for example). We have only had interest from faculty in Finance and this has resulted in web-course development for engineering students.

Recruiting approach - The difficulty in focusing in on a target student population, affected our recruiting and we saw very few students. Since redefining the population, we now:

- Speak with over 50 students per year., and more than half of those 1-on-1

- We have an student Engineering Ambassador for the program

- We participate as the National Society of Black Engineers advisor and are one of the lead faculty members of the COEM's Virtual Development Center for Women

- We give presentations at Honors College seminars, COEM recruiting events, and National Merit recruiting events

Placement and Career Development - This is a major issue with our students. As we get more graduates, we have more experience to draw on. As a result of feedback on surveys of students and alumni we provide or do the following for students and for industry: 
- Placement contacts for graduates and summer jobs

- Space for employer recruiting materials

- Pass out program materials at the UA career fair in the Fall

- Participate in the Microsoft Academic Advisory Council (generates free software and employment opportunities for students)

There has been an issue with some students/companies with the BA degree designation. The difficulty from the student side is that a student can do both a focus and complement in traditional BS degree areas (Engineering and Finance for example) and get a BA degree. Some companies have had difficulty in understanding that often this is a BA program with more technical content than the traditional university BS degrees.

Seminars - Management and Design - In the initial plan for the program, we envisioned a series of 1-credit seminars that would be given by faculty affiliated with the program. Funds were used to develop these classes. It probably would have been better to spend more money for seminar course development and for archiving. By and large, these seminar courses ran one time only and were not cost effective. There was little archived for future use and for transfer to other universities. The student reviews were mixed as the classes required significantly more time than expected and the topics were not interesting to the large majority of students. Based on this feedback and the eventual expense required to maintain the selection of classes, the following changes were made:

- Dropped the 1-credit idea. Used funding to support supported existing 3-credit classes

- Constructed a list of UA classes that would meet the requirement. The list is dynamic and students can make suggestions for additions and deletions

- Accept and encourage independent study and internship position projects to fulfill this requirement. We require a proposal, final report, and a final presentation for each 3-credit course granted.

Although these changes have been good, when we moved from sponsored seminars, we lost student cohesion and program identity. We will probably start a program seminar series where students can present material on co-ops, projects, and independent studies.

College Advisory Committee, University Advisory Committee/Industry Advisory Committee - The program was initially started by a faculty team within the Systems and Industrial Engineering Department. The program is really a College program, but it is viewed by students and most faculty as an SIE program since most of the administration is within SIE and the team has been entirely in SIE. This is a problem in terms of visibility within the College as SIE has lower visibility. This hurts student recruiting, but the main impact is that it reduces the ability of the program to generate more faculty interest and more interest from outside funding sources.

The Program Director Position is all encompassing (advising, administration, evaluation, fund raising). The job can get a bit tiring and we need more energy from the position or more people working on this role. This job would be easier if there was an advisory/advisor team. It is 
difficult for the Director to reserve time to get out and speak with industry. A large local industry base would really help, but we simply do not have this in Tucson. Even 100 miles away is far enough to preclude fund/interest raising trips. The directorship of the program is not part of the standard teaching load and has been done primarily as an overload (like a typical research project).

We have formed a University advisory committee, but this should have started much earlier in the history of the program. This could have been used to build stronger ties to Fine Arts and Social Sciences. We probably missed opportunities at the University level for additional visibility. The committee helps to get faculty involved. In the future, we hope to enlist a formal industrial advisory committee and this group will deal with student question "what can I do with this degree?" The plan is to use program alumni and companies that have recruited students.

Acknowledgements - The BAE project has been strongly supported by NSF under Award Number 9555057. Also, the author wishes to thank the initial reviewer for taking time and giving the paper a thorough review. Your comments were a great help in getting more substance into the paper.

\section{Bibliographic Information}

[1] Gerard H. (Gus) Gaynor, “The Engineer As A Professional: What Does It Mean, What Does It Take?" Innovation Management Institute, 1997 Professional Activities Conference Proceedings, Institute for Electrical and Electronics Engineering, 1997.

[2] University Of Western Australia Submission To The Review Of The Bachelor Of Engineering Student Services http://www.ems.uwa.edu.au/ARCHIVE/Review/Review/studentservices.html.

[3] Thomas K. Miller III, H. Troy Nagle, Clarence J. Maday, David E. Van den Bout, James J. Brickley, Tony L. Mitchell, and ohn C. Kelly, "Chapter 5 The Engineering Entrepreneurs Program - Early Design Experiences: A Manual for Addressing Design Early in the Engineering Curriculum" the SUCCEED Early Design Megaproject Report, May, 1995.

[4] A. Blanton Godfrey, Quality Digest, 1997 http://www.qualitydigest.com/april97/html/qmanage.html.

[5] Pender M. McCarter, Today's Engineer Magazine (summer 1998) and in IEEE Fort Worth Section Newsletter SIGNALS August 1998.

[6] Ralph Castain. Harvey Mudd College Physics webpage http://www.physics.hmc.edu/Alumni/quotes.html.

[7] Sharon Beder, 'Beyond Technicalities: Expanding Engineering Thinking' Journal of Professional Issues in Engineering, 125(1), pp. 12-18, January 1999.

[8] US National Research Council Board on Engineering Education.. "Engineering Education: Designing an Adaptive System," 1995.

[9] Review of Engineering Education. Changing the Culture: Engineering Education into the Future, Review Report, Institution of Engineers, Australia, Canberra, 1996.

\section{Biographical Information}

Jeff Goldberg is an Associate Professor in Systems and Industrial Engineering at the University of Arizona. He also serves as director of the BA in Engineering Program and is a past Associate Editor of Engineering Education. Jeff is one of the leaders in the UA's Virtual Development Center. His education research areas include increasing retention and web-based education. 